\title{
MINI-CPT: A continuous performance test program for the Tandy PC-8 Pocket Computer
}

\author{
DAVID A. BREMER \\ Central Oahu Community Mental Health Center, Pearl City, Hawaii
}

\begin{abstract}
MINI-CPT programs the miniature PC-8 computer (2K RAM) to administer a continuous performance test. After training to criterion, MINI-CPT presents a randomized series of 360 stimuli at 1-sec intervals. Upon completion of the 6-min task, statistics including reaction time (RT) mean, standard deviation, and distribution; errors of omission and commission; a percent correct score adjusted for response bias; and RTs for each of the 90 targets are displayed or printed via a PC-3 printer. User options include selecting immediate RT feedback, limiting the task to 3 min, and designating the randomization seed to generate replicable stimulus sequences. MINI-CPT provides a portable, inexpensive measure of attention suitable for use in field research in attentionaldeficit disorders, circadian rhythm disturbances due to shift work or jet lag, and, in neuropsychological rehabilitation, as a directed-attention training device with immediate feedback.
\end{abstract}

A continuous performance test (CPT) sensitive to impairment associated with organic brain dysfunction was originally described by Rosvold, Mirsky, Sarason, Bransome, and Beck (1956) using a complex mechanical memory drum, tachistoscope, and timing apparatus. Subsequently, the CPT has been adapted to the study of attention and impulsiveness in children using other laboratory instruments (Sykes, Douglas, \& Morgenstern, 1973), slide presentation of stimuli (Rapport, DuPaul, Stoner, \& Jones, 1986), and Apple-II and IBM PC computers (Conners, 1985; Eliason \& Richman, 1987; Klee \& Garfinkle, 1983; Sostek, Buchsbaum, \& Rapoport, 1980).

MINI-CPT programs the miniature $(14 \times 7 \times 1 \mathrm{~cm}) \mathrm{PC}-8$ computer (2K RAM) to present a randomized series of 360 stimuli at 1-sec intervals, with 90 of the stimuli designated as targets. Reaction times (RTs) are recorded in 25msec increments, and errors of omission and commission are tallied. Upon completion of the 6-min task, a statistical report is generated for Minutes 2-6.

\section{Set Up}

After turning on the PC-8, which retains MINI-CPT in write-protected constant memory, the user presses the DEF key to permit execution of the program from different designated lines. Pressing the $=$ key selects the standard test administration beginning on line 1 ; whereas the F-key option (line 2) sets a flag triggering immediate RT feedback after each response to target. On line 3, MINICPT displays " $S$ " prompting input of an integer as a randomization seed for determining the stimulus sequence.

I thank Richard Kravetz for his advice on design of the MINI-CPT for use with children and James Craine for suggestions regarding neuropsychological applications of the task. Requests for reprints or instructions should be addressed to David A. Bremer, Central Oahu Community Mental Health Center, Hawaii State Department of Health, 860 4th St., Pearl City, HI 96782.
After displaying "?", as a prompt for selection of 3- or 6-min test duration, MINI-CPT (lines 4-8) takes about $15 \mathrm{sec}$ to randomly generate a replicable sequence for the 360 test stimuli such that 15 of every 60 stimuli are targets and each target is preceded by 1 to 9 nontargets.

\section{Training and Test}

Upon completion of the randomization process, MINICPT (lines 10-14) presents training stimuli at 1-sec intervals, with one target every 3 rd to 5 th trial until 3 correct responses to target occur without omission or commission error. After the training criterion is attained, MINI-CPT (lines 15-18) shifts, without hesitation, to presentation of the random series of 360 stimuli, recording RT to each target and tallying errors. Errors of commission are scored only for the 180 nontargets that do not immediately follow a target.

\section{Stimulus Presentation, RT Timing, and Feedback}

A subroutine (lines 20-26) presents stimuli, times responses, and provides RT feedback for the training and test routines. If the previously generated random stimulus series calls for a nontarget, MINI-CPT (line 20) randomly selects and displays for $207 \mathrm{msec}$ a nontarget letter from a pool of eight letters. As an unobtrusive indicator of the shift from training to task, two nontarget stimuli $(\mathrm{E}, \mathrm{F})$ are added to the nontarget pool $(\mathrm{H}, \mathrm{I}, \mathrm{K}, \mathrm{L}, \mathrm{M}, \mathrm{N})$, and two nontargets $(\mathrm{X}, \mathrm{Y})$ that were included in the pool during training are dropped. If a target is called for, the target letter $O$ is displayed for $207 \mathrm{msec}$.

Line 21 checks to ensure that the response key (key 5 enlarged by a transparent plastic hemispherical computer "foot"-Radio Shack part no. 64-2365) is not already depressed at $212 \mathrm{msec}$ after stimulus onset. If such an anticipatory response to a target has occurred, the trial is scored as an omission but coded as an anticipatory error 
for the data analyses and report. This step is necessary to prevent a continuously depressed key from being scored as a correct response.

Lines 22 and 23 serve as a timing loop (25-msec cycle). If no response occurs within 25 cycles $(837 \mathrm{msec}$ after stimulus onset), an omission is scored for targets and the program proceeds to the next stimulus. If the loop is interrupted by a 5 keypress, then RT, or ".,", feedback is provided (lines 24-25).

\section{Report}

When the test is completed, pressing the DEF key and then the Z key initiates data analysis. MINI-CPT (lines 30-39) takes 2 min to compute the RT mean, standard deviation, and distribution in milliseconds; errors of omission and commission; and percent correct adjusted for response bias: $\% \mathrm{C}=$ hit rate $\times(1$-false alarm rate $) \times$ $100 \%$. These statistics plus a listing of raw RT data for the 90 target trials can be viewed line by line on the PC- 8 liquid-crystal display or printed out using a Tandy PC-3 printer. The RTs for each trial and number of errors for each minute are presented in a compressed coded format, where $\mathrm{A}=225 \mathrm{msec}, \mathrm{B}=250 \mathrm{msec}, \ldots, \mathrm{Y}=825 \mathrm{msec}$, and $\mathrm{Z}$ indicates an omission. For example, "HJGNZPZMHFIGLLG3" codes 1 min of data, with RT ranging from $F=350 \mathrm{msec}$ to $P=600 \mathrm{msec}$ with two omissions (Zs) and three errors of commission.

\section{Application}

The MINI-CPT has potential application where cost and portability of measurement instruments are factors. The battery-operated PC-8, which lists for $\$ 59.95$, can be used in field settings where electricity is not readily available or where bringing the instrument to the sample is advantageous. In addition to research on attentional deficits in children, the MINI-CPT is a convenient task for in vivo measurement of circadian alertness rhythms in shift work or jet lag studies. The MINI-CPT also may be applicable in neuropsychological rehabilitation as a take-home, directed attention training task with immediate feedback. In the MINI-CPT, the target letter $O$ was selected as being clearly distinguishable from the nontarget letter pool (EFHIKLMNXY), but for other applications where a more difficult discrimination task may be desirable, any of the 65 ASCII printable characters available on the PC-8 could be programmed into the 11-character stimulus selection string (line 20). The lack of compatibility for direct electronic data transfer to any other type of computer for sample statistical analyses could be a limitation in some applications; however, the entire set of raw RT and error data for a single administration of the CPT is contained in six 16-character strings easily entered manually via a computer keyboard.

\section{REFERENCES}

Conners, C. K. (1985). The computerized continuous performance test. Psychopharmacology Bulletin, 21, 891-892.

Euason, M. J., \& Richman, L. C. (1987). The continuous performance test in learning disabled and nondisabled children. Journal of Leaming Disabilities, 20, 614-619.

KLEe, S. H., \& GARFINKLE, B. D. (1983). The computerized continuous performance task: A new measure of inattention. Joumal of $A b$ normal Child Psychology, 11, 487-496.

Rapport, M. D., DuPaul, G. J., Stoner, G., Jones, J. T. (1986). Comparing classroom and clinic measures of attention deficit disorder: Differential, idiosyncratic, and dose-response effects of methylphenidate. Journal of Consulting \& Clinical Psychology, 54, 334341.

Rosvold, H. E., Mirsky, A. F., Sarason, I., Bransome, E. D., \& BECK, L. H. (1956). A continuous performance test of brain damage. Journal of Consulting Psychology, 20, 343-350.

Sostek, A. J., Buchsbaum, M. S., \& RAPOPORT, J. L. (1980). Effects of amphetamine on vigilance performance in normal and hyperactive children. Journal of Abnormal Child Psychology, 8, 491-500.

Sykes, D. H., Douglas, V. I., \& MORGenSTERN, G. (1973). Sustained attention in hyperactive children. Journal of Child Psychology \& Psychiatry, 14, 213-220.

Set Up

1 "=": CLEAR : GOTO 3

2 "F": CLEAR :F=1

3 PRINT = PRINT : WAIT 12: DIM X\$(6): INPUT "S";S,M

$4 D=5-3 \star(M=3)$ : FOR I $=1$ TO $4 S:]=$ RND 1: NEXT I: IF $S=\varnothing$ THEN RANDOM

5 FOR $M=1$ TO $D+1$ : RESTORE : FOR $H=1$ TO RND 4: READ G: NEXT $H$ :

FOR $H=1$ TO $9: J=$ VAL MID $\$(\operatorname{STR} \$ G, H, 1):$ IF $J=\varnothing$ THEN 7

6 FOR $I=1$ TO J:L=LEN X\$(M):K= RND $(L+1): X \$(D)=\operatorname{LEFT~}(X \$(M), K-1)+$

STR $\$ H+R I G H T \$(X \$(M), L+T-K): X \$(M)=X \$(\phi):$ NEXT I 
7 NEXT H: NEXT M: RANDOM

8 DATA $532211061,44311011 \%, 533110101,44221101 \%$

Training and Test

$10 \mathrm{~J}=$ RND 4+2: FOR I=] TO $\mathrm{J}$ : GOSUB 20: IF T>25 THEN 13

$11 \mathrm{c}=\mathrm{C}+1$ : IF I $<\mathrm{J}$ THEN LET $c=\varnothing$

12 GOTO 14

13 IF I $=\mathrm{J}$ THEN LET $C=\varnothing$

14 NEXT I: IF $C<3$ THEN $1 \varnothing$

15:FOR $M=\oint$ TO $D: X \$(M)="$ ": FOR $N=1$ TO 15:J=VAL $\operatorname{MIDS}(X \$(M+1), N, 1)+1:$

FOR I=1 TO J: GOSUB 2ø: IF I $<\mathrm{J}$ THEN IF I $>1$ THEN IF $\mathrm{T}<26$

THEN LET $E=E+1$

16 IF $\mathrm{I}<\mathrm{J}$ THEN 18

$17 \times S(M)=X \$(M)+$ CHR $\$(T+64)$

18 NEXT I: NEXT $N: X \$(M)=X \$(M)+$ CHR $\$(E+48): E=\emptyset:$ NEXT M: WAIT : PRINT " END ": END

Subroutine: Stimulus Presentation, RT Timing, and Feedback

26 YS $=$ MIDS ("OEFHIKLMNXY", (RND $\left.8+2 \star(C<3))^{\star}(I<J)+1,1\right): T=\not$ : PRINT " ", Y\$

27 IF INKEY\$ $=" 5 "$ THEN LET T=27: FOR $W=1$ TO 76: NEXT $W:$ GOTO 26

$22 \mathrm{~T}=\mathrm{T}+1$ : IF $\mathrm{T}=26$ THEN 26

23 IF INKEY\$ $<>$ " 5 " THEN 22

$24 Y \$=" . ":$ IF I $=J$ THEN IF $F=1$ THEN LET $Y \$=S T R \$$ INT $(2 \not \varnothing+2.5 T)$

25 PRINT " $, Y \$:$ FOR $W=1$ TO 46-3.1T: NEXT $W$

26 RETURN

Report

3ø "Z": PRINT = LPRINT : USING "\#\#\#": FOR U=D TO 2 STEP -3:

$A=\emptyset: B=\varnothing: E=\varnothing: 0=\varnothing$

31 FOR $M=1$ TO U: FOR $N=1$ TO 15:R=25*( $\operatorname{ASC} \operatorname{MIDS}(X \$(M), N, 1)-64)+2 \not \varnothing$ :

IF $R>825$ THEN LET $R=999: 0=0+1$

$32 A=A+R: B=B+R R:$ NEXT $N: E=E+\operatorname{ASC} \operatorname{MID} \$(X \$(M), 16,1)-48:$ NEXT M

33 PRINT 15U;"S";A/15U;"M"; SQR ((B-AA/15U)/(15U-1));"SD"

34 PRINT $0 ; " 0 " ; E ; " E " ; 1 \not \emptyset \star(1-0 / 15 U) \star(1-E / 3 \not U)+.5 ; " q C ":$ LPRINT " ": NEXT U 
14 BREMER

35 PRINT "L RT FREQ \& CUM\%":Q=ø: FOR $R=65$ TO $91: P=\varnothing:$ FOR $M=1$ TO $D$ :

FOR $N=1$ TO 15

$36 P=P+(\operatorname{MID} \$(X \$(M), N, 1)=$ CHR $\$ R):$ NEXT $N: N E X T M: Q=Q+P$ :

$Z S=\operatorname{STRS}((R-64) \star 25+2 \phi \sigma)$

37 IF $R>89$ THEN LET $Z \$=": 0 "+$ STR $(R-9 \phi)$

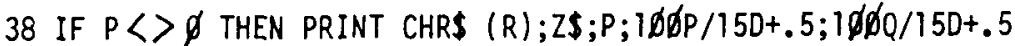

39 NEXT R: LPRINT " : FOR M=ø TO D: PRINT X\$(M): NEXT M:

PRINT S;"S";F;"F"

(Manuscript received September 27, 1988;

revision accepted for publication November 30,1988 .) 